\title{
JOURNAL.RU
}

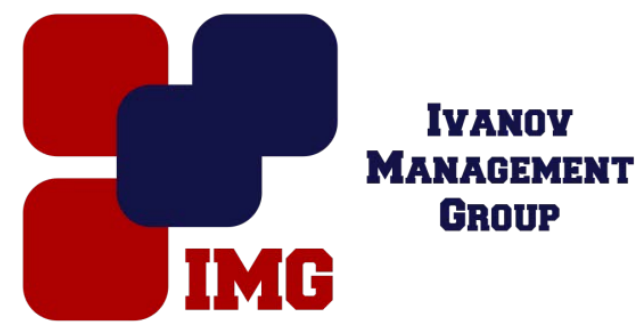

Расторопнова Ю.С. Уфимский государственный авиационный технический университет Уфа, Россия

doi: 10.18411/lj-25-12-2016-3-13

idsp 000001:lj-25-12-2016-3-13

\section{Методические подходы к управлению текучестью кадров}

\section{Аннотация}

В данной статье рассматривается внешние движение кадров. Каковы положительные и отрицательные стороны текучести кадров и как они влияют на производительность труда и какие экономические потери для предприятия несёт в себе данное понятие.

Ключевые слова: движение кадров, текучесть, управление персоналом, аутплейсмент, потеря кадров.

Анализируя текучесть рабочей силы, нужно начинать с изучения понятия «движение кадров». В прошлые годы и в настоящее время эта проблема привлекает экономистов, потому что текучесть кадров наносит несомненный вред предприятиям и стране в целом. Но, также, есть несомненные плюсы данной тенденции.

Целью данного исследования является определение минусов и плюсов текучести кадров.

Для начала раскроем понятие "текучесть кадров". Текучесть добровольный официальный уход наемного работника из одной организации (фирмы) в другую на основании самостоятельно принятого им решения.

Текучесть кадров в пределах 3-5\% от численности персонала считается естественным. Такое процентное соотношение не требует каких-либо чрезвычайных мер со стороны кадровых служб и руководства предприятия. В основном этот небольшой процент работников покидает рабочее место в связи с выходом на пенсию, беременностью, либо другим личным причинам. На их место приходят новые сотрудники. Это нормальный процесс каждого предприятия.

Но, чаще всего, к сожалению для предприятий, текучесть превышает допустимый порог. В связи с оттоком кадров увеличиваются издержки. Как 
правило, такие процессы связаны с экономико-политической ситуацией в стране. Бывают и совсем краховые ситуации, когда на предприятиях увольнялись сотрудники целыми отделами из-за ряда недовольств. Пока идет подбор новых сотрудников и проходит адаптация, производство практически приостанавливает работу.

Как правило, высокая текучесть кадров указывает на недостатки в управлении персоналом и на серьезные проблемы предприятия в целом.

Необходимо исходить из конкретной ситуации на предприятии. Представленная ниже методика предполагает упорядоченную поэтапную деятельность, осуществлять которую будет непосредственно кадровая служба предприятия. Можно представить в виде поэтапных стадий деятельность по управлению текучестью кадров.

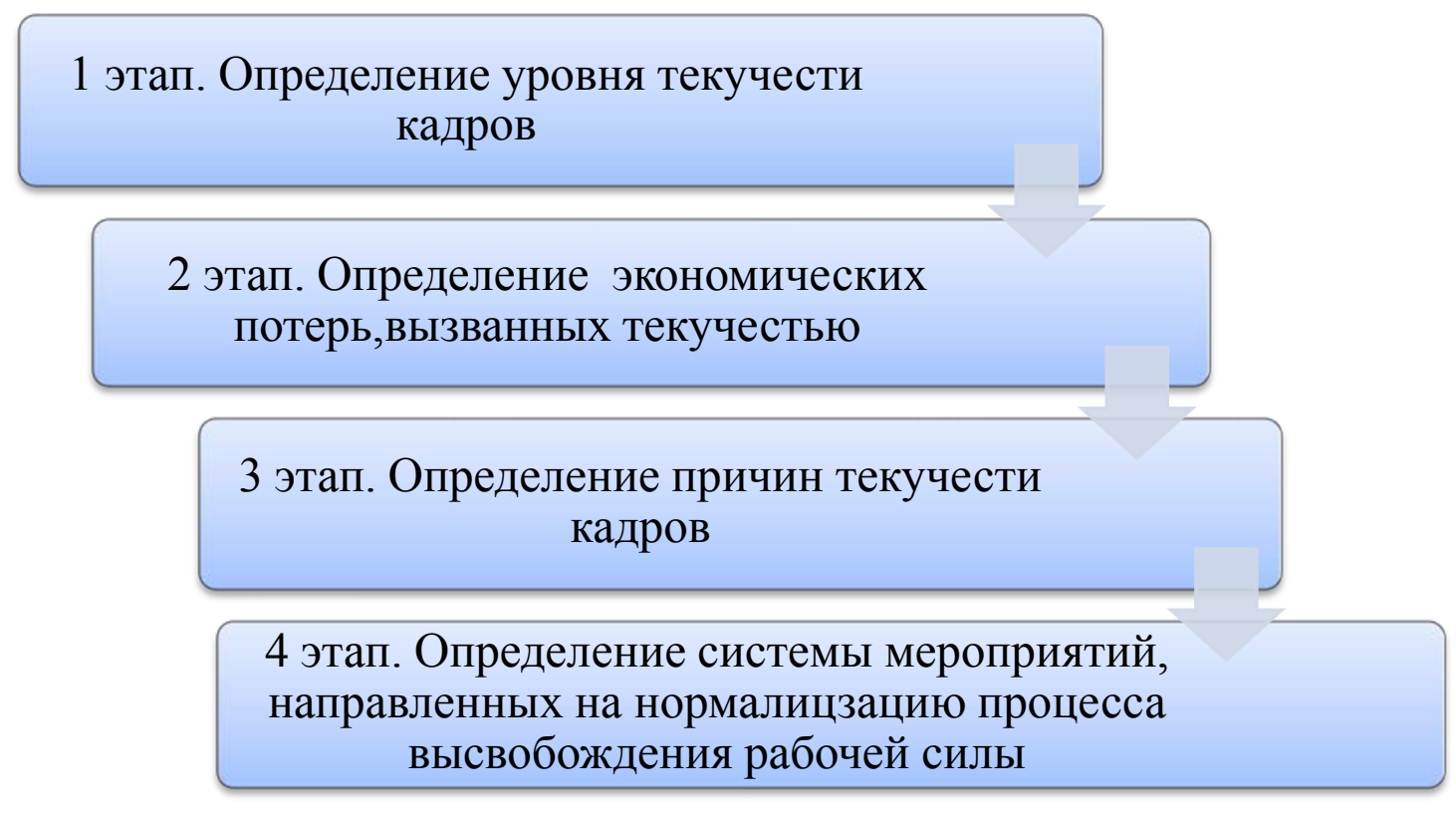

Этапь управления текучестью кадров

Рассмотрим подробно каждый из представленных этапов.

На первом этапе нужно ответить на вопрос: уровень текучести кадров настолько ли высок, что приводит к экономическим потерям? Нужно провести анализ динамики трудовых показателей предприятия за последние годы.

Одним из самых трудоемких является второй этап, потому что для его проведения необходимы специальные данные. Следует не пренебрегать нормирование труда , призванное выявить резервы производительности труда.

Следующие показатели дадут нам общую картину о величине потерь кадров:

- потеря рабочего времени. Незаполненное рабочее место не производит продукцию, пока происходит увольнение и принятие нового сотрудника; 
- потери, вызванные проведением процедуры увольнения. Выплаты пособий увольняющимся сотрудникам. Нужно учесть, что суммы выплат будут разными, так как и статьи увольнений разные;

- потери, вызванные проведением процедуры найма работников на вакантное рабочее место;

- затраты на поиск кандидатов (объявления в средствах массовой информации, рекламные щиты с объявлением о приеме на работу и др.);

- затраты на отбор кандидатов (затраты рабочего времени кадровой службы, осуществляющей процедуры отбора - тестирование, собеседование, просмотр анкет и др., и финансовые затраты на те же процедуры);

- затраты на обучение принятого на работу сотрудника;

- затраты на проведение трудовой адаптации работника, обучение на рабочем месте (наставничество, самообучение, помощь коллег по работе и др.);

- затраты на обучение с отрывом от производства.

Как правило, текучесть кадров связана с несовершенством систем управления предприятием либо « по собственному желанию», скрывающий в себе подтекст данных подпунктов:

1) низкая заработная плата,

2) задержки заработной платы,

3) тяжелые и опасные условия труда,

4) неприемлемый режим работы.

Представим «личные причины» в таблице 1.

Таблииа1.

Пример простейшего исследования мотивов выбытия работников с предприятия (результат)

\begin{tabular}{|l|l|}
\hline \multicolumn{2}{|c|}{ По какой причине Вы меняли работу? } \\
\hline Низкая заработная плата & \multicolumn{1}{|c|}{$24 \%$} \\
\hline $\begin{array}{l}\text { Отсутствие перспектив } \\
\text { роста }\end{array}$ & $11 \%$ \\
\hline $\begin{array}{l}\text { Не сложившиеся } \\
\text { отношения с } \\
\text { руководством }\end{array}$ & \multicolumn{1}{|c|}{$6 \%$} \\
\hline $\begin{array}{l}\text { Неудобный график } \\
\text { работы }\end{array}$ & $5 \%$ \\
\hline $\begin{array}{l}\text { Неудобное } \\
\text { расположение работы }\end{array}$ & $5 \%$ \\
\hline Другое & $11 \%$ \\
\hline
\end{tabular}

Таким образом, мы провели три этапа исследований.

4 этап: определение системы мероприятий, направленных на нормализацию процесса высвобождения рабочей силы, совершенствования процедуры увольнения, преодоление излишнего уровня текучести.

В качестве эффективной меры можно принять во внимание аутплейсмент, что означает помощь увольняемым сотрудникам - психологические, консультационные и информационные беседы с увольняемыми. Эти меры позволят снизить обращения с претензиями от уволенных, в том числе и 
судебных исков, а также остаться в доброжелательных отношениях с увольняемым сотрудником.

В заключении необходимо отметить, что многие предприятия, особенно в крупных городах, перекладывают данные вопросы на специализированные кадровые агентства. Однако, стоить заметить, верным искоренением проблемы кадровой утечки является не обращение в какие-либо агентства, а решение вопросов собственными силами предприятия, так как опытный руководитель должен знать, по каким причинам произошла данная проблема.

\section{Литература}

1. Аверин А.Н. Управление персоналом, кадровая и социальная политика в организации / А.Н. Аверин. - М.: Издательство РАГС, 2005. - 224c.

2. Агашкова, А.П. Есть такое явление - текучесть / А.П. Агашкова // Секреты управления персоналом. - 2007. - № 7. $\square 180$ c

3. Голубков, Е. П. Анализ текучести кадров на предприятии /Е.П. Голубков // Менеджмент в России. - 2011. - №4. $\square 230$ с

4. Управление человеческими ресурсами: Учебник для вузов /М.И. Соколова, А.Г. Дементьева. - М.: Изд-во Проспект, 2005. - 240с. 